THU0271

EMERGENCE OF SEVERE SPONDYLOARTHROPATHY RELATED ENTHESEAL PATHOLOGY FOLLOWING VEDOLIZUMAB THERAPY FOR INFLAMMATORY BOWEL DISEASE

S. Dubash ${ }^{1,2}$, T. Marianayagam ${ }^{3}$, T. Al-Araimi ${ }^{4}$, C. Pagnoux ${ }^{4}$, A. Weizman ${ }^{4}$, M.- $^{-}$ L. Tran Minh ${ }^{5}$, M. Allez ${ }^{5}$, P. Richette ${ }^{5}$, H. Marzo-Ortega ${ }^{1,2}$, D. McGonagle ${ }^{1,2} .{ }^{1} \mathrm{NIHR}$ Leeds Biomedical Research Centre, Leeds Teaching Hospitals, ${ }^{2}$ Leeds Institute of Rheumatic and Musculoskeletal Medicine, University of Leeds, Leeds; ${ }^{3}$ Rheumatology, East and North Hertfordshire NHS Trust, Stevenage, UK; ${ }^{4}$ Division of Rheumatology, Mount Sinai Hospital, Toronto, Canada; ${ }^{5}$ Hopital Lariboisiere, University Hospitals Group, Paris, France

Background: The Spondyloarthritides $(\mathrm{SpA})$ and inflammatory bowel disease (IBD) share common aetiopathogenetic and clinical manifestations. Vedolizumab, a humanised IgG1 monoclonal antibody to $\alpha 4 \beta 7$ integrin, has been approved for the treatment of inflammatory bowel disease (IBD) and inhibits $\alpha 4 \beta 7$ integrin at the gut level. Vedolizumab therapy for IBD has been associated with mild SpA related features including sacroilitis and synovitis. Herein, we report the emergence of severe SpA under therapy with Vedolizumab.

Objectives: We conducted a clinical evaluation of 7 vedolizumab treated patients with IBD that developed severe active SpA and/or enthesopathy with the aim of characterising the vedolizumab associated SpA/entheseal flares.

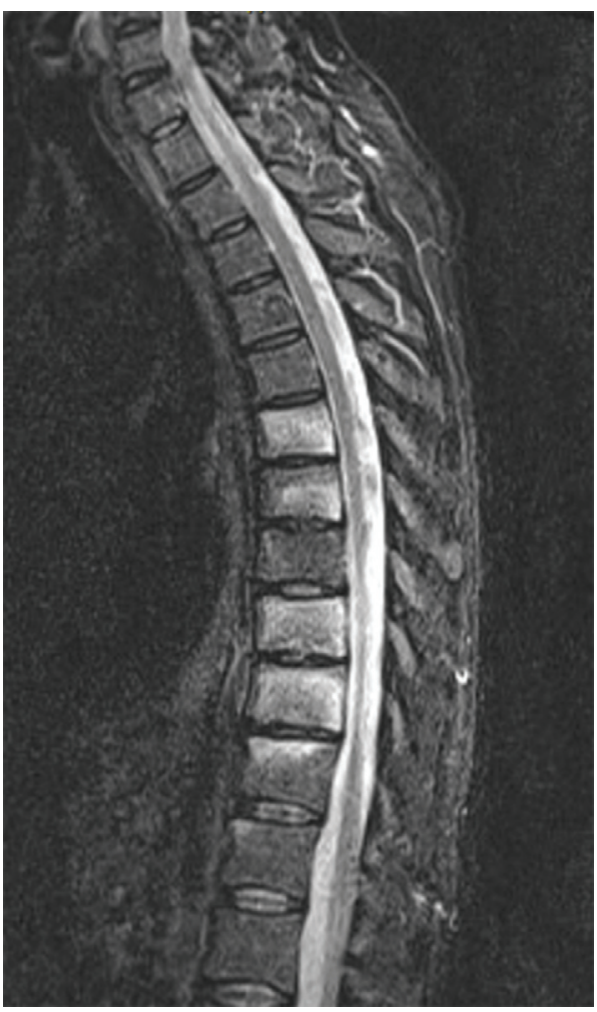

Methods: Vedolizumab treated IBD patients with SpA/enthesopathy were identified across four hospitals. We identified clinical, biochemical and imaging characteristics within routine case records as part of a clinical evaluation.
Results: We identified 6/7 subjects that developed de novo SpA/enthesopathy and 1/7 (subject 1 ) with a severe flare of pre-existing $\mathrm{SpA}$. There were $3 / 7$ patients hospitalised due to the severity of skeletal disease. The median time from vedolizumab initiation to flare was 10 weeks (table 1 below). Subject 4 developed newonset SpA with severe spinal vertebral end-plate oedema (T6-12) and inflammatory Romanus lesions (L3-4) (image below). Acute sacroiliitis was identified on $\mathrm{MRI}$ in 3 subjects, one of which showed evidence of radiographic bilateral grade 2 sacroiliitis. In at least 4 cases the IBD disease activity was considered to be low or well controlled. Following vedolizumab discontinuation, so far 3 patients have switched to alternative biologic therapies including certolizumab pegol, golimumab, and 1 subject to sulphasalazine.

$\mathrm{cpd}=$ cigarettes per day, $\mathrm{MTX}=$ methotrexate, $\mathrm{AZA}=$ azathioprine, $\mathrm{OC}=$ oral cortico steroid, Pred=prednisolone, $\mathrm{nr}=$ non radiographic, $\mathrm{MRI}+\mathrm{ve}=\mathrm{MRI}$ positive, $\mathrm{XR}+\mathrm{ve}=$ radiograph positive, $\mathrm{NA}=$ not available

Conclusions: This case series demonstrates severe vedolizumab associated $\mathrm{SpA} /$ enthesopathy that resulted in hospitalised cases. The severity of vedolizu mab related SpA flares is relatively severe disease in comparison to the literature. We recognise that vedolizumab is efficacious in IBD, however our observations highlight the need to monitor symptoms to identify patients that develop axial or peripheral SpA several weeks from commencing vedolizumab.

Disclosure of Interest: None declared

DOI: 10.1136/annrheumdis-2018-eular.5649

\section{THU0272 1 WHICH SCORING METHOD DEPICTS SPINAL RADIOGRAPHIC DAMAGE IN (EARLY) AXIAL SPONDYLOARTHRITIS BEST? FIVE-YEAR RESULTS FROM THE DESIR COHORT}

S. Ramiro $^{1}$, P. Claudepièrre ${ }^{2}$, A. Sepriano ${ }^{1}$, M. van Lunteren ${ }^{1}$, A. Molto $^{3}$, A. Feydy ${ }^{3}$, M.A. D' Agostino ${ }^{4}$, D. Loeuille ${ }^{5}$, M. Dougados ${ }^{3}$, M. Reijnierse ${ }^{1}$, D. van der Heijde ${ }^{1} .{ }^{1}$ Leiden University Medical Center, Leiden, Netherlands; ${ }^{2}$ Université Paris Est Créteil, Créteil; ${ }^{3}$ Paris Descartes University; ${ }^{4}$ Université Versailles-Saint Quentin en Yvelines Boulogne-Billancour, Paris; ${ }^{5}$ University of Nancy, Nancy, France

Background: Scores capturing spinal radiographic damage have been proposed and compared in r-axSpA. In early phases of the disease, it is still unknown how these perform.

Objectives: To compare the performance of different radiographic scores of the spine in patients with early axial spondyloarthritis (axSpA).

Methods: Five-year follow-up data (baseline, 2 and 5 years) from the DESIR cohort, including patients with early axSpA, have been used. Spine (cervical, thoracic and lumbar), sacro-iliac joints (SI), and hips were scored on radiographs centrally and independently by 3 readers (scores averaged) for the calculation of different radiographic methods (table 1). Following the OMERACT filter, scores were compared with regard to truth, discrimination (sensitivity to change and reliability) and feasibility. Baseline status scores, and 2- and 5 year change scores were calculated for each of the methods, as well as the proportion of patients with a net change (number of patients with a positive change minus number of patients with a negative change divided by all patients) above the smallest detectable change (SDC). The proportion of total variance explained by the patient ('true variance') was calculated for the change scores of the different instruments and their components using ANOVA, as a measure of reliability.

Results: In total, 699 patients (mean age 34 (SD 9) years, $47 \%$ males) had at least one radiograph available. Mean baseline and 5 year change scores were: mSASSS 0.4(SD 1.5) and 0.4 (1.8), RASSS 0.5 (1.6) and 0.6 (2.2), SASSS 0.2 (0. 7) and 0.3 (1.1), BASRI spine 1.0 (1.2) and $0.2(0.6)$, BASRI spine with thoracic spine: $1.1(1.4)$ and $0.3(0.7)$, BASRI total $1.0(1.3)$ and $0.3(0.6)$ and BASRI total with thoracic spine $1.2(1.4)$ and $0.3(0.7)$, respectively. SDCs and proportion of 2 and 5 year change, including net change, are presented in the table 1 . The

\begin{tabular}{|c|c|c|c|c|c|c|c|}
\hline Subject number & 1 & 2 & 3 & 4 & 5 & 6 & 7 \\
\hline Age, M/F & $28, M$ & $48, M$ & $33, \mathrm{~F}$ & $50, \mathrm{M}$ & $35, F$ & $40, \mathrm{~F}$ & $21, F$ \\
\hline Hospitalised & $\mathrm{Y}$ & $\mathrm{N}$ & $\mathrm{N}$ & $\mathrm{N}$ & Y & Y & $\mathrm{N}$ \\
\hline $\begin{array}{l}\text { Vedolizumab } \\
\text { exposure (weeks) }\end{array}$ & 14 & 20 & 20 & 6 & 8 & 10 & 5 \\
\hline SpA type & $\begin{array}{l}\text { per+axSpA }(\mathrm{MRI}+\mathrm{ve}, \\
\text { perifacetal spinal } \\
\text { vertebral oedema) }\end{array}$ & $\begin{array}{c}\text { per+axSpA } \\
\text { (acute sacroilitis } \\
\text { MRI+ve) }\end{array}$ & $\begin{array}{c}\text { axSpA } \\
\text { (MRI } \\
+ \text { ve sacroiliitis) }\end{array}$ & $\begin{array}{c}\mathrm{nr}-\mathrm{axSpA}(\mathrm{MRI}+\mathrm{ve} \text {, extensive thoracolumar } \\
\text { vertebral oedema/osteitis and inflammatory } \\
\text { corner lesions) }\end{array}$ & $\begin{array}{c}\mathrm{nr}- \\
\text { axSpA }\end{array}$ & $\begin{array}{l}\text { Enthesitis/ } \\
\text { periostitis distal tibio- } \\
\text { fibular (MRI+ve) }\end{array}$ & $\begin{array}{l}\text { per+axSpA (MRI } \\
\quad+\text { ve and XR } \\
\text { +ve sacroliliitis)) }\end{array}$ \\
\hline HLA-B27 & $\mathrm{N}$ & NA & NA & $\mathrm{N}$ & Y & NA & $\mathrm{N}$ \\
\hline Smoker (cpd) & 15 & NA & NA & 25 & $\mathrm{~N}$ & NA & $\mathrm{N}$ \\
\hline EIMs (Uveitis, PsO) & $\mathrm{N}$ & $\mathrm{N}$ & $\mathrm{PsO}$ & $\mathrm{N}$ & $\mathrm{PsO}$ & $\mathrm{N}$ & $\mathrm{N}$ \\
\hline IBD activity & Low & NA & NA & High & Low & Low & Low/well controlled \\
\hline $\mathrm{CRP}$ at flare $(\mathrm{mg} / \mathrm{l})$ & 216 & $<5$ & $<5$ & 24 & 24 & 28 & 55 \\
\hline $\begin{array}{l}\text { Concomitant } \\
\text { immunosuppressive } \\
\text { therapy }\end{array}$ & MTX $15 \mathrm{mg} \mathrm{s} / \mathrm{c} /$ week & AZA $150 \mathrm{mg} /$ day & $\begin{array}{c}\text { OC (Pred } \\
0.5 \mathrm{mg} / \text { day }\end{array}$ & Nil & Nil & OC (4 mg Pred) & Nil \\
\hline
\end{tabular}


mSASSS and the RASSS performed the best in terms of capturing the signal (i.e. positive change) despite the noise (i.e. negative change), which is taken into account in the net change calculation.

The proportion of variance explained by the patient for the radiographic scores was highest for the mSASSS and RASSS, both for status and progression scores (e.g. $70 \%$ for mSASSS 69\% for RASSS 2 year progression). However, the proportion of patient variance in the thoracic segment of the RASSS was unsatisfactory (36\% for 2 year progression, compared to $54 \%$ lumbar segment and $73 \%$ cervical segment).

In what concerns feasibility, all scores seemed feasible, but the thoracic segment was missing in up to $7 \%$ of the cases, thus not allowing computation of BASRI modifications to include that segment.

Abstract THU0272 - Table 1. Two- and 5-year change, above the smallest detectable change, across the different radiographic scores

\begin{tabular}{|c|c|c|c|c|c|c|c|c|c|c|}
\hline & \multicolumn{5}{|c|}{ 2-year Change > SDC } & \multicolumn{5}{|c|}{ 5-year Change > SDC } \\
\hline & $\mathrm{N}$ & SDC & \begin{tabular}{|l} 
Positive \\
change \\
N (\%)
\end{tabular} & $\begin{array}{l}\text { Negative } \\
\text { change } \\
\mathrm{N}(\%)\end{array}$ & $\begin{array}{c}\text { Net } \\
\text { change } \\
\mathrm{N}(\%)\end{array}$ & $\mathrm{N}$ & SDC & $\begin{array}{l}\text { Positive } \\
\text { change } \\
\mathrm{N}(\%)\end{array}$ & $\begin{array}{l}\text { Negative } \\
\text { change } \\
\mathrm{N}(\%)\end{array}$ & $\begin{array}{c}\text { Net } \\
\text { change } \\
\mathrm{N}(\%)\end{array}$ \\
\hline \begin{tabular}{|l} 
mSASSS $(0.72)$ \\
\end{tabular} & 488 & 0.9 & $29(6)$ & $6(1)$ & $23(5)$ & 372 & 1.1 & $41(11)$ & $3(1)$ & $38(10)$ \\
\hline 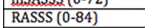 & $\frac{480}{484}$ & 0.9 & $\frac{25(5)}{26(5)}$ & $2(0.4)$ & $\frac{25(5)}{24(5)}$ & $\frac{372}{370}$ & $\frac{1.2}{1.2}$ & $\frac{41(11)}{54(15)}$ & $\frac{3(1)}{1(0.3)}$ & $53(14)$ \\
\hline \begin{tabular}{|l|} 
SASSS (0-72) \\
\end{tabular} & 499 & 0.8 & $13(3)$ & $0(0)$ & $13(3)$ & 389 & 1.2 & $36(9)$ & $0(0)$ & $36(9)$ \\
\hline \begin{tabular}{|l} 
BASSSI (00/2L) \\
BASI spine $(0-12)$
\end{tabular} & 484 & 0.8 & \begin{tabular}{|l}
$130(8)$ \\
40
\end{tabular} & $22(5)$ & $\frac{13(3)}{18(4)}$ & $\begin{array}{l}3899 \\
371\end{array}$ & $\frac{1.2}{0.7}$ & $\begin{array}{l}36(9) \\
39(11)\end{array}$ & $2(0.5)$ & $\frac{36(1)}{37(10)}$ \\
\hline $\begin{array}{l}\text { BARI spine with } \\
\text { thoracic }(0-16)\end{array}$ & 360 & 0.6 & $35(10)$ & $17(5)$ & $18(5)$ & 267 & 0.9 & $31(12)$ & $2(1)$ & $29(11)$ \\
\hline \begin{tabular}{|l|}
$\mid$ thoracaic $(0.16)$ \\
BASRI total $(0-16)$
\end{tabular} & 480 & 0.6 & $41(9)$ & $22(6)$ & $19(4)$ & 368 & 0.8 & $41(11)$ & $2(0.5)$ & $39(11)$ \\
\hline $\begin{array}{l}\text { BASRI total with } \\
\end{array}$ & 358 & 0.7 & $19(4)$ & $4(1)$ & $15(3)$ & 266 & 0.9 & $32(12)$ & $2(1)$ & $30(11)$ \\
\hline
\end{tabular}

Conclusions: The existing scoring methods to assess spinal radiographic damage performed well in early phases of axSpA. The mSASSS and RASSS captured most change. There was no clear gain in additionally scoring the thoracic spine for the RASSS while an increased noise was introduced. The mSASSS remains the most sensitive and valid scoring method in axSpA, including early phases of the disease.

Disclosure of Interest: None declared

DOI: 10.1136/annrheumdis-2018-eular.2882

\section{THU0273 PREVALENCE OF VERTEBRAL FRACTURES IN ANKYLOSING SPONDYLITIS: A META-ANALYSIS}

J. Sahuguet ${ }^{1}$, J. Mancini ${ }^{2}$, P. Lafforgue ${ }^{3},{ }^{3}$ T. Pham. ${ }^{1}$ Aphm, Hopital Sainte Marguerite; ${ }^{2}$ Aix Marseille Univ, Inserm, Ird, Umr912 Sesstim; ${ }^{3}$ Aix Marseille Univ, Aphm, Hopital Sainte Marguerite, Marseille, France

Background: Osteoporosis is a well-recognised feature of ankylosing spondylitis (AS). Patients with AS have an increased risk of vertebral fractures (VF) but prevalence of VF is variable across studies from $4 \%$ to $42 \%$. The diagnosis of VF is still problematic because frequently asymptomatic and sometimes difficult to differentiate from vertebral deformities which are not fractures.

Objectives: The aim of our study was to determine the prevalence of VF in AS and the risk factors associated.

Methods: Two independent investigators conducted a search in Medline and Cochrane databases, including cohorts, cross-sectional, and case-control studies that had assessed the prevalence of VF in patients with AS fulfilling the modified New York criteria. We collected data about study design, demographics, disease activity and severity (HLA B27 antigen status, BASDAI, BASFI, ASDAS, mSASSS, CRP, ESR, treatment history), bone mineral density, method of VF assessment (method of $X$-rays reading, number of readers) and characteristics of VF (number, prevalence, grade).

Results: Among 434 screened studies, 17 were eligible for meta-analysis. The pooled VF prevalence in patients with AS was $19 \%\left(95 \% \mathrm{Cl} 14 \%>24 \%, \mathrm{I}^{2} 90.5 \%\right)$ (figure 1). The CRP $(p<0.001)$ and mSASSS $(p=0.046)$ scores were associated with a higher risk of VF. When focusing only on moderate to severe VF, HLA B27 antigen $(p=0.046)$, lumbar spine osteoporosis $(p=0.018)$ and osteopenia $(p=0.024)$, hip BMD $(p=0.024)$, CRP $(p=0.004)$, ESR $(p<0.001)$, and Genant method $(p=0.009)$ were associated with higher risk of VF.

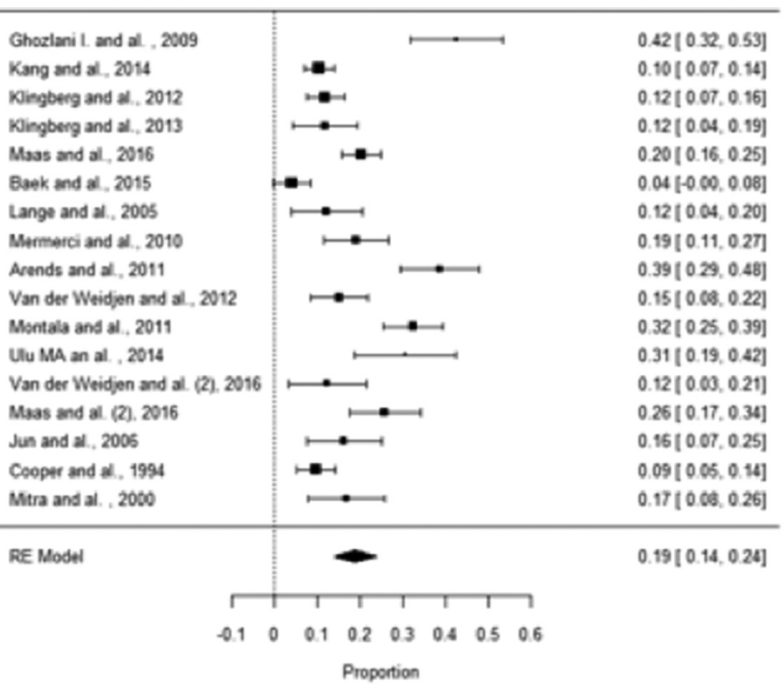

Conclusions: Despite a large heterogeneity among studies, the prevalence of VF in AS patients is high. CRP and mSASSS scores were associated with the prevalence of all VF. Classical VF risk factors, such as osteoporosis, were associated only with moderate and severe VF.

Disclosure of Interest: None declared

DOI: 10.1136/annrheumdis-2018-eular.5191

\section{THU0274 ASSESSMENT OF RADIOGRAPHIC SACROILIITIS ON ANTERO-POSTERIOR LUMBAR RADIOGRAPHS AS COMPARED TO CONVENTIONAL PELVIC RADIOGRAPHS IN PATIENTS WITH AXIAL SPONDYLOARTHRITIS}

${ }^{1}$ V. Rios Rodriguez, M. Llop ${ }^{1}$, M. Protopopov ${ }^{1}$, J. Sieper ${ }^{1}$, H. Haibel ${ }^{1}$, M. Rudwaleit ${ }^{2}$, D. Poddubnyy ${ }^{1,3} .{ }^{1}$ Rheumatology, Charité Universitätsmedizin, Berlin; ${ }^{2}$ Internal Medicine and Rheumatology, Klinikum Bielefeld Rosenhöhe, Bielefeld; ${ }^{3}$ German Rheumatism Research Centre, Berlin, Germany

Background: EULAR guidelines consider conventional radiography of sacroiliac joints (SIJs) as the first recommended imaging method in case of suspected axial spondyloarthritis (axSpA). 'However, it is not clear whether sacroiliac joints can be reliably assessed on anteroposterior (AP) lumbar radiographs, which are often performed as a part of the diagnostic work-up in patients presented with back pain.

Objectives: To investigate reliability and validity of radiographic sacroilitis assessment on AP lumbar radiographs as compared to conventional pelvic $X$ rays in patients with axSpA.

Methods: Patients from the GErman SPondyloarthritis Inception Cohort (GESPIC) were selected based on the availability of sets of pelvic and AP lumbar radiographs with visible SIJs at baseline and after 2 years of follow-up. Two trained readers ( $M L$ and $V R$ ) scored the images independently and in a random order according to the radiographic system of the modified New York (mNY) criteria (grade 0 to 4 ). The sacroilitis sum score $(0-8)$ was calculated as a sum of the mean grades of 2 readers for the right and left SIJ. We assessed intra- and interreader reliability using intraclass correlation coefficients (ICC) of the sacroilitis sum scores. Patients were classified as having radiographic axSpA ( $r$-axSpA) when both readers agreed on the presence of definite radiographic sacroiliitis according to the $\mathrm{mNY}$ criteria, and non-radiographic axSpA (nr-axSpA) otherwise. Results: A total of 226 sets radiographs were scored from the 113 patients included in the present study. Intra-observer agreement was good to excellent for 